\title{
Eficiência simbiótica de progenitores de cultivares brasileiras de feijão-caupi ${ }^{1}$
}

\author{
Symbiotic efficiency in parents of Brazilian cultivars of the cowpea
}

\author{
Rosa Maria Cardoso Mota de Alcantara ${ }^{2 *}$, Gustavo Ribeiro Xavier ${ }^{3}$, Norma Gouvêa Rumjanek ${ }^{3}$, Maurisrael de \\ Moura Rocha ${ }^{4}$ e Jackeline dos Santos Carvalho ${ }^{5}$
}

\begin{abstract}
RESUMO - Devido à variabilidade das leguminosas quanto à eficiência da fixação biológica de nitrogênio (FBN), tem sido enfatizada a importância do melhoramento genético vegetal no favorecimento da fixação do nitrogênio. Este estudo teve como objetivo avaliar a eficiência simbiótica de progenitores de cultivares brasileiras de feijão-caupi e dar suporte científico à inclusão da FBN ao programa de melhoramento genético da cultura do feijão-caupi no Brasil. O experimento foi conduzido em Teresina, Piauí. Utilizou-se delineamento experimental em blocos casualizados em esquema fatorial 6 x 5, com três repetições, sendo seis fontes de $\mathrm{N}$ : quatro estirpes de bactérias diazotróficas (BR 3267, BR 3299, BR 3262 e INPA 03-11B), um tratamento com nitrogênio mineral e outro sem inoculação e sem N; e cinco genótipos de feijão-caupi: quatro progenitores (TVu 1190, Pitiúba, CNC 0434 e Alagoano) e uma cultivar (BRS Guariba). Na análise de variância utilizou-se software SAS e as médias foram comparadas pelo teste Tukey. O progenitor Alagoano destacou-se dos demais em eficiência de nodulação, foi superior ao Pitiúba em massa seca de nódulos e diferiu do TVu 1190 em nitrogênio acumulado na parte aérea. Para nitrogênio derivado da fixação biológica verificou-se uma variação média de 49,42 a 65,50\%. Nos componentes de produção, o Alagoano se destacou em massa de vagem, comprimento de vagem e massa de 100 sementes. Concluiu-se que os progenitores avaliados são responsivos a FBN e que há indícios de especificidade entre os progenitores e as estirpes de rizóbio. O progenitor Alagoano apresenta resultados mais promissores nos componentes de nodulação e produção.
\end{abstract}

Palavras-chave: Feijão-caupi-melhoramento genético. Plantas-inoculação. Plantas-efeito do nitrogênio.

\begin{abstract}
Among the progenitors, the Alagoano shows most promising results in components of nodulation and production. Due to the variability of leguminous plants as regards their efficiency in the biological fixation of nitrogen (BFN), the importance of plant breeding to improve nitrogen fixation has been emphasized. The objective of this study was to evaluate the symbiotic efficiency of parents of Brazilian cultivars of the cowpea, and give scientific support to the inclusion of BFN in the breeding program for the cowpea crop in Brazil. The experiment was conducted in Teresina, Piauí. An experimental design of randomized blocks in a 5 x 6 factorial arrangement was used, with three replications, consisting of six sources of N: four strains of diazotrophic bacteria (BR 3267, BR 3299, BR 3262 and INPA 03-11B); one treatment with mineral nitrogen and another with no inoculation and no N, and five cowpea genotypes: four parents (TVu 1190, Pitiúba, CNC 0434 and Alagoano) and one cultivar (BRS Guariba). For the variance analysis SAS software was used, and the averages compared by Tukey test. The parent, Alagoano, stood out from the others in nodulation efficiency, was higher than Pitiúba for nodule dry mass, and differed from TVu 1190 in nitrogen accumulation in the shoots. For nitrogen derived from biological fixation there was a mean variation of from 49.42 to $65.50 \%$. As for production components, the Alagoano excelled in pod weight, pod length and 100 seed weight. It was concluded that the evaluated parents are responsive to BFN, and that there is evidence for specificity between the parents and the strains of rhizobia. Of the parents, the Alagoano presents the most promising results for the components of nodulation and production.
\end{abstract}

Key words: Cowpea-breeding. Plants-inoculation. Plants-nitrogen effect.

\footnotetext{
*Autor para correspondência

'Recebido para publicação em 03/09/2012; aprovado em 08/10/2013

Parte da Tese de Doutorado do primeiro autor, apresentada ao Programa de Pós-Graduação em Agronomia/Ciência do Solo, DCS/UFRRJ

2Embrapa Meio-Norte, Av. Duque de Caxias, 5650, Buenos Aires, Teresina-PI, Brasil, 64.006-220, rosa.m.mota@embrapa.br

${ }^{3}$ Embrapa Agrobiologia, Rodovia BR 465 km 7, Antiga Rio São Paulo Seropédica-RJ, Brasil, 23.890-000 gustavo.xavier@embrapa.br, norma. rumjanek@embrapa.br

${ }^{4}$ Embrapa Meio-Norte, Av. Duque de Caxias, 5650, Buenos Aires, Teresina-PI, Brasil, 64.006-220 maurisrael.rocha@embrapa.br

${ }_{5}^{5}$ Universidade Federal do Piauí, Campus Universitário Ministro Petrônio Portella, Ininga, Teresina-PI, Brasil, 64.049-550, jackeline.s.carvalho@bol.com.br
} 


\section{INTRODUÇÃO}

A tecnologia de inoculação de bactérias de interesse biotecnológico na agricultura tem contribuído para reduzir o uso e o consequente impacto dos agroquímicos no meio ambiente. Os benefícios dos processos ecológicos desempenhados por estes microrganismos por meio da fixação biológica de nitrogênio (FBN), do controle biológico, da promoção de crescimento vegetal e da solubilização de nutrientes, têm contribuído para aumentar a sustentabilidade dos sistemas agrícolas (MARTINS et al., 2003).

Nas leguminosas, a FBN é bastante variável dependendo da espécie e tem sido observado grande potencial para aumento da contribuição desta, por meio do melhoramento genético. Estudos desta natureza vêm sendo desenvolvidos na Europa, desde a década de 40, visando a seleção e o melhoramento do trevo (Trifolium pratense), trevo subterrâneo (Trifolium subterraneum), fava (Vicia faba), soja (Glycine max), alfafa (Medicago sativa) e ervilha (Pisum sativum) para o incremento da nodulação e consequentemente da FBN (HERRIDGE; ROSE, 2000).

No Brasil, o maior exemplo da importância benéfica da inclusão da FBN no melhoramento vegetal foi com a soja [Glycine $\max ($ L.) Merrill]. A Comissão Nacional da Soja, baseada nas pesquisas com inoculação, enfatizou em 1960 a necessidade de dar prioridade à FBN como parte integrante do programa de melhoramento. A partir de então, fertilizantes nitrogenados foram substituídos pela inoculação com estirpes de bactérias diazotróficas simbióticas denominadas vulgarmente de rizóbios. Atualmente todas as cultivares melhoradas de soja possuem eficiência na FBN dispensando o uso de adubos nitrogenados (ALVES; BODDEY; URQUIAGA, 2003).

Segundo Singh et al. (2002), os programas de melhoramento de feijão-caupi (Vigna unguiculata (L.) Walp.) costumam, tradicionalmente, enfocar o caráter precocidade, resistência a pragas e doenças, armazenamento, produtividade e características dos grãos. Geralmente, estes programas não visam à melhoria da contribuição da FBN para o favorecimento do crescimento vegetal e da produção de grãos desta cultura.

No Senegal o principal programa de melhoramento do feijão-caupi tem como enfoque: maturação precoce, altas produtividades, resistência a doenças, pragas e plantas invasoras. Nos últimos anos, os melhoristas desse país, constataram a necessidade de incluir no melhoramento, genótipos com potencial para alta fixação de $\mathrm{N}_{2}$ visando obter cultivares com eficiência simbiótica (NDIAYE; SPENCER; GUEYE, 2000).

No Brasil, o programa de melhoramento do feijãocaupi coordenado pela Embrapa Meio-Norte, tem como objetivos principais: o desenvolvimento de cultivares com porte adequado para exploração pela agricultura familiar e pela agricultura empresarial; o incremento da produtividade e da resistência a estresses hídricos; o aumento dos teores de proteína, ferro e zinco e a melhoria da qualidade visual e culinária dos grãos (FREIRE FILHO, 2011).

Constata-se, portanto, uma lacuna com relação à FBN no referido programa, não havendo conhecimento da eficiência simbiótica dos progenitores que constituem a base genética das cultivares brasileiras do feijão-caupi. Por outro lado, vários estudos de avaliação das estirpes de rizóbio em associação às cultivares recomendadas têm indicado respostas bastante diferenciadas quanto à habilidade dos genótipos em fixar nitrogênio (CHAGAS JÚNIOR et al., 2010; GUALTER et al., 2011; LACERDA et al., 2004; MARTINS et al., 2003; SOARES et al., 2006; ZILLI et al., 2006; ZILLI et al., 2009a; ZILLI et al., 2009b).

Neste contexto, este estudo teve como objetivo avaliar a eficiência simbiótica de progenitores de cultivares brasileiras de feijão-caupi, identificando associações eficientes entre genótipos e estirpes de rizóbio, que possam dar suporte científico à inclusão da FBN no programa de melhoramento genético vegetal da cultura do feijão-caupi.

\section{MATERIAL E MÉTODOS}

O experimento foi conduzido no campo experimental da Embrapa Meio-Norte, no município de Teresina, PI ( $5^{\circ} 5^{\prime} \mathrm{S}$ e $42^{\circ} 48^{\prime} \mathrm{O}$ e a $72 \mathrm{~m}$ de altitude), no período de maio a agosto de 2010, em solo classificado como ARGISSOLO VERMELHO-AMARELO Distrófico (SANTOS et al., 2006), com as seguintes características químicas (camada $0-20 \mathrm{~cm}): \mathrm{pH}\left(\mathrm{H}_{2} \mathrm{O}\right)$ 5,75; $\mathrm{Al}^{+3} 0,05 \mathrm{cmol}_{\mathrm{c}} \mathrm{dm}^{-3} ; \mathrm{Ca}^{+2} 6,33 \mathrm{cmol}_{\mathrm{c}} \mathrm{dm}^{-3} ; \mathrm{Mg}^{+2}$ $1,44 \mathrm{cmol}_{\mathrm{c}} \mathrm{dm}^{-3}$; K 0,47 $\mathrm{cmol}_{\mathrm{c}} \mathrm{dm}^{-3} ; \mathrm{P} 12,15 \mathrm{mg} \mathrm{dm}^{-3} \mathrm{e}$ Matéria orgânica $10,50 \mathrm{~g} \mathrm{~kg}^{-1}$.

Utilizou-se o delineamento experimental de blocos ao acaso em esquema fatorial 6 × 5 com três repetições. O fatorial foi constituído por seis fontes de $\mathrm{N}$ (quatro estirpes, um tratamento com nitrogênio mineral e outro sem inoculação e sem N) e cinco genótipos de feijão-caupi (quatro progenitores e uma cultivar). Os progenitores avaliados foram: TVu 1190, Pitiúba, CNC 0434 e Alagoano e a cultivar foi a BRS Guariba, incluída como parâmetro de comparação aos progenitores. As estirpes de rizóbio empregadas foram: BR 3267, BR 3299, BR 3262 e INPA 03-11B.

Os progenitores e a cultivar foram obtidos do Banco Ativo de Germoplasma da Embrapa MeioNorte e as estirpes provenientes da coleção de bactérias diazotróficas da Embrapa Agrobiologia. Os progenitores TVu 1190 e CNC 0434 são originários da 
Nigéria e apresentam 10,29 e 27,94\%, respectivamente, de frequência relativa do genótipo no pedigree (FRGP) das cultivares brasileiras melhoradas. O Alagoano e Pitiúba são de origem brasileira e possuem FRGP equivalente a 2,94 e $35,29 \%$, respectivamente.

A parcela experimental correspondeu a $24,75 \mathrm{~m}^{2}$, com onze linhas de plantio de 4,50 m de comprimento, tendo como área útil as cinco linhas centrais, destinando-se $1 \mathrm{~m}$ nas extremidades e três fileiras nas laterais como bordadura. $\mathrm{O}$ espaçamento utilizado foi de $0,50 \mathrm{~m}$ entre fileiras e $0,25 \mathrm{~m}$ entre plantas, o que correspondeu a 18 plantas por fileira. A inoculação foi realizada $5 \mathrm{~h}$ antes do plantio com inoculante turfoso contendo cerca de $10^{9}$ células de rizóbio $\mathrm{g}^{-1}$ do inoculante. A dosagem utilizada foi na proporção de $500 \mathrm{~g} \mathrm{de}$ inoculante para $50 \mathrm{~kg}$ de sementes (VARGAS et al., 2004).

No plantio foram semeadas três sementes para posterior desbaste que ocorreu aos 15 dias após emergência (DAE), deixando-se uma planta por cova. $\mathrm{Na}$ adubação dos tratamentos nitrogenados foram utilizados $20 \mathrm{~kg} \mathrm{ha}^{-1}$ de N (MELO et al., 2005), tendo como fonte ureia. $\mathrm{O}$ fornecimento de nitrogênio foi feito de forma parcelada, sendo $50 \%$ no plantio e $50 \%$ aos 20 DAE. De acordo com a análise do solo, foi realizada uma adubação de fundação com fósforo na proporção de $20 \mathrm{~kg} \mathrm{ha}^{-1}$ de $\mathrm{P}_{2} \mathrm{O}_{5}$, tendo como fonte superfosfato simples, conforme recomendação de Melo et al. (2005). Devido às condiçõos climáticas, com ocorrência de esparsas precipitações pluviométricas no período de condução do experimento $(86,9 \mathrm{~mm})$, utilizou-se irrigação suplementar por aspersão com lâmina de água total correspondendo a $431 \mathrm{~mm}$, conforme recomendado por Bastos et al. (2008).

Na fase inicial da floração (38 a 45 DAE) avaliaramse os componentes de nodulação: número de nódulos (NN), massa seca de nódulos (MSN), massa seca da parte aérea (MSPA), nitrogênio acumulado na parte aérea (NAPA), eficiência de nodulação (ENOD) e nitrogênio derivado da fixação biológica (NDFB). Realizou-se a amostragem para os componentes de nodulação na terceira linha de plantio, coletando-se três plantas inteiras. As plantas foram separadas em raiz e parte aérea por um corte no ponto de inserção cotiledonar.

As raízes foram lavadas sobre peneira para evitar perda de nódulos, sendo estes destacados das raízes para determinação do NN e MSN. Colocou-se a parte aérea fresca das plantas em estufa de circulação de ar a $60-70^{\circ} \mathrm{C}$ até atingir peso seco constante $( \pm 72 \mathrm{~h})$. Após secagem a parte aérea foi moída e pesada para determinação da MSPA e do N total, determinado pelo método Kjeldahl (BREMNER, 1996).

O NAPA foi calculado a partir do teor de $\mathrm{N}$ total multiplicado pela massa de matéria seca da parte aérea (CLAESSEN, 1997) e a ENOD foi determinada dividindo-se o $\mathrm{N}$ total da parte aérea pela massa seca de nódulos (MELO; ZILLI, 2009). O NDFB foi determinado pela técnica da abundância natural de ${ }^{15} \mathrm{~N}$ (SHEARER; KOHL, 1986). Utilizaram-se amostras da parte aérea das plantas de feijão-caupi, obtidas na fase de floração, estádio R2 e também amostras da parte aérea de espécies espontâneas não-leguminosas, coletadas aleatoriamente na área experimental. As espécies espontâneas amostradas foram: malva branca (Sida cordifolia), caruru (Amarantuhs viridis) e capim pé de galinha (Eleusine indica). $\mathrm{O}$ material coletado foi seco a $62{ }^{\circ} \mathrm{C}$, moído e analisado para abundância natural de ${ }^{15} \mathrm{~N}$ (OKITO et al., 2004), por meio da seguinte fórmula (equação 1):

$\left.N D F B=\left[\left(\delta^{15} N c-\delta^{15} N f c\right) / \delta^{15} N c-B\right)\right] \times 100$

onde $\delta^{15} \mathrm{Nc}$ e $\delta^{15} \mathrm{Nfc}$ correspondem aos valores de abundância natural de ${ }^{15} \mathrm{~N}$ das plantas controle e do feijão-caupi, respectivamente. $\mathrm{O}$ valor $\mathrm{B}$ é uma constante relacionada ao processo de discriminação isotópica de ${ }^{15} \mathrm{~N}$ pelo processo da $\mathrm{FBN}$, considerado para feijão-caupi como - 1,759 delta (BELANE; DAKORA, 2010).

$\mathrm{Na}$ fase de maturação das vagens (65 a 76 DAE) foram avaliados os seguintes componentes de produção: massa de vagem (MV), comprimento de vagem (CV), número de vagem por planta (NVP), número de grãos por vagem (NGV), massa de 100 sementes (M100S) e rendimento médio de grãos (RMG). Para a determinação da massa e comprimento de vagens foi considerada a média de cinco vagens retiradas da área útil. O número de vagens por planta foi feito a partir da relação total de vagens da área útil pelo número de plantas desta área. Na mensuração do número de grãos por vagem utilizaram-se as vagens obtidas do número de vagens por planta, as quais foram trilhadas para contagem dos grãos. Determinou-se a massa de 100 sementes pela contagem e pesagem de 100 grãos e o rendimento médio foi determinada a partir da pesagem de grãos da área útil com umidade corrigida para $13 \%$.

Os dados de nodulação e produção foram testados quanto à normalidade (teste de Lillefors) e homogeneidade dos resíduos (teste de Cochran) e submetidos à análise de variância. $\mathrm{Na}$ análise de variância foi utilizado o software SAS e as médias foram comparadas pelo teste de Tukey a 5\% de probabilidade.

\section{RESULTADOS E DISCUSSÃO}

$\mathrm{Na}$ análise de variância dos componentes de nodulação, a interação entre os fatores, fontes de nitrogênio $(\mathrm{FN})$ e genótipos $(\mathrm{G})$ foi significativa apenas para nitrogênio derivado da fixação biológica (NDFB). Com relação aos fatores isolados, massa seca de nódulos 
(MSN), nitrogênio acumulado na parte aérea (NAPA), eficiência de nodulação (ENOD) e nitrogênio derivado da fixação biológica (NDFB) foram afetados de modo significativo pelo fator genótipos, mas não apresentaram significância para o fator fontes de nitrogênio (Tabela 1).

Para MSN, a amplitude de resultados foi de 35,99 a 78,86 mg planta $^{-1}$. O progenitor Alagoano apresentou superioridade significativa em relação ao Pitiúba, com um acréscimo de 54,36\% e não diferiu da cultivar BRS Guariba e dos demais progenitores (Tabela 2). Embora o feijão-caupi possua grande capacidade de fixar $\mathrm{N}$, tem sido observada uma variação na MSN entre genótipos, o que tem sido atribuído à diferente habilidade de fixação de $\mathrm{N}$ apresentada entre diferentes genótipos (XAVIER et al., 2006).

Gualter et al. (2008) e Xavier et al. (2008) obtiveram valores de MSN inferiores aos deste estudo, avaliando a cultivar BRS Guariba inoculada com as estirpes BR 3262 e BR 2001, nas mesmas condições edafoclimáticas. Acredita-se que os menores resultados obtidos por estes autores, tenham sido em virtude de que estes experimentos foram conduzidos em solos anteriormente cultivados com leguminosas, e que provavelmente o maior aporte de $\mathrm{N}$ ao solo contribuiu para uma menor nodulação e consequentemente menor MSN. Na região Pré-Amazônica maranhense, em solos de primeiro cultivo, a BRS Guariba inoculada com as estirpes avaliadas neste trabalho, apresentou valores para MSN semelhantes aos obtidos com os progenitores (GUALTER et al., 2011).

Em NAPA, o progenitor Alagoano foi superior ao TVu 1190 (Tabela 2) com incremento de 28,42\% e não diferiu da cultivar e dos demais progenitores. Os resultados obtidos foram semelhantes aos verificados em ensaios com outras cultivares, nos quais os valores do NAPA situaram-se na faixa de 113 a $200 \mathrm{mg}$ planta $^{-1}$ (ALMEIDA et al., 2010; GUALTER et al., 2011; MELO; ZILLI, 2009; ZILLI et al., 2006).

A maioria dos genótipos que apresentaram maior MSN também apresentou maior NAPA, indicando que a boa nodulação refletiu na fixação do nitrogênio. A MSN tem sido indicada como um parâmetro estritamente

Tabela 1 - Resumo da análise de variância das variáveis de nodulação de genótipos de feijão caupi associados a estirpes de rizóbio

\begin{tabular}{|c|c|c|c|c|c|c|c|}
\hline \multirow{2}{*}{ FONTES DE VARIAÇÃO } & \multirow{2}{*}{ GL } & \multicolumn{6}{|c|}{ QUADRADO MÉDIO } \\
\hline & & $\mathrm{NN}$ & $\mathrm{MSN}$ & MSPA & NAPA & ENOD & NDFB \\
\hline Blocos & 2 & $183,57^{*}$ & $9,98 *$ & $1418,85^{*}$ & $2824,55^{*}$ & $894,49 *$ & $385,06^{*}$ \\
\hline Fontes N (FN) & 5 & $115,95^{\mathrm{ns}}$ & $1,45^{\mathrm{ns}}$ & $87,35^{\mathrm{ns}}$ & $91,75^{\text {ns }}$ & $709,94^{\mathrm{ns}}$ & $244,71^{\mathrm{ns}}$ \\
\hline Genótipos (G) & 4 & $109,33^{\mathrm{ns}}$ & $5,58 *$ & $286,79^{\text {ns }}$ & $650,72 *$ & $669,50 *$ & $407,32 *$ \\
\hline $\mathrm{FN} \times \mathrm{G}$ & 20 & $72,08^{\mathrm{ns}}$ & $0,88^{\mathrm{ns}}$ & $146,33^{\mathrm{ns}}$ & $303,56^{\mathrm{ns}}$ & $578,45^{\mathrm{ns}}$ & $372,71 *$ \\
\hline Resíduo & 58 & 83,65 & 1,90 & 156,37 & 267,45 & 622,65 & 118,48 \\
\hline $\mathrm{CV}(\%)$ & & 36,35 & 38,50 & 33,22 & 33,54 & 35,57 & 18,65 \\
\hline
\end{tabular}

NN-número de nódulos $\left(\mathrm{n}^{\mathrm{o}}\right.$ planta $\left.^{-1}\right)$; MSN-massa seca de nódulos $\left(\mathrm{mg} \mathrm{planta}^{-1}\right)$; MSPA-massa seca da parte aére $\left(\mathrm{g}\right.$ planta $\left.{ }^{-1}\right)$; NAPA-nitrogênio acumulado na parte aérea (mg planta-1); ENOD-eficiência de nodulação $\left(\mathrm{mg} \mathrm{mg}^{-1}\right)$; NDFB-nitrogênio derivado da fixação biológica (\%); ns-não significativo, *significativo a $5 \%$ de probabilidade do teste $\mathrm{F}$

Tabela 2 - Valores médios de variáveis de nodulação de genótipos de feijão-caupi

\begin{tabular}{lcccc}
\hline \multirow{2}{*}{ GENÓTIPOS } & MSPA & MSN & NAPA & \multirow{2}{*}{ ENOD } \\
\cline { 2 - 4 } & g planta $^{-1}$ & mg planta $^{-1}$ & mg mg $^{-1}$ & $0,30 \mathrm{c}$ \\
TVu 1190 & $32,80 \mathrm{a}$ & $63,93 \mathrm{ab}$ & $130,91 \mathrm{~b}$ & $0,90 \mathrm{~b}$ \\
Pitiúba & $36,92 \mathrm{a}$ & $35,99 \mathrm{~b}$ & $145,75 \mathrm{ab}$ & $0,50 \mathrm{~b}$ \\
CNC 0434 & $38,68 \mathrm{a}$ & $58,63 \mathrm{ab}$ & $157,21 \mathrm{ab}$ & $1,80 \mathrm{a}$ \\
Alagoano & $43,68 \mathrm{a}$ & $78,86 \mathrm{a}$ & $182,89 \mathrm{a}$ & $0,60 \mathrm{~b}$ \\
BRS Guariba & $36,14 \mathrm{a}$ & $40,27 \mathrm{ab}$ & $154,09 \mathrm{ab}$ & 0,82 \\
Média & 37,64 & 55,53 & 154,17 & 2 \\
\hline
\end{tabular}

MSPA-massa seca da parte aérea; MSN-massa seca de nódulos; NAPA-nitrogênio acumulado na parte aérea; ENOD-eficiência de nodulação. Médias seguidas de letras distintas, na coluna, diferem entre si pelo teste de Tukey a $5 \%$ de probabilidade 
relacionado à $\mathrm{FBN}$, tendo sido recomendado como descritor para programas de melhoramento que objetivam o aumento da fixação de $\mathrm{N}_{2}$ (BELANE; DAKORA, 2010). O NAPA tem sido considerado como indicador de estirpes com potencial para compor inoculantes com eficiência simbiótica. Portanto, considerando-se estes descritores, observa-se que os genótipos Alagoano, CNC 0434 e Guariba apresentaram potencial satisfatório para FBN.

Em ENOD, o progenitor Alagoano foi significativamente superior aos outros progenitores e a cultivar BRS Guariba. A ENOD do Alagoano foi maior na proporção de $66,67 \%$ em relação a cultivar e $83,33 \%$ quando comparado ao TVu 1190. Estes dados diferem dos obtidos por Melo e Zilli (2009) com a cultivar BRS Guariba, a qual apresentou ENOD superior $\left(1 \mathrm{mg} \mathrm{mg}^{-1}\right)$ ao deste estudo $\left(0,6 \mathrm{mg} \mathrm{mg}^{-1}\right)$. Considera-se que os melhores resultados obtidos por estes autores, tenham sido devido à condução do experimento em casa de vegetação, onde geralmente a inoculação é mais eficiente. Com relação ao Alagoano, houve maior acúmulo de $\mathrm{N}$ e, portanto, uma boa eficiência, visto que a ENOD é um parâmetro indicativo da ocorrência de uma associação simbiótica eficaz. Em termos de NDFB verificou-se variação média de 49,42 a 65,50\% entre os genótipos avaliados (Tabela 3 ).

$\mathrm{Na}$ literatura verificam-se diferentes variações para nitrogênio fixado biologicamente. Herridge, Peoples e Boddey (2008) obtiveram variações na faixa de 8 a $97 \%$ entre 16 genótipos de feijão-caupi de origem africana. Yusuf et al. (2008) observaram variações em torno de 19 a $46 \%$ com os genótipos Sample-7 e IT96D-724, enquanto que Belane e Dakora (2010) verificaram uma amplitude de 63,5 a 86,7\% para 30 genótipos africanos. Estas variações foram atribuídas a fatores genéticos da planta hospedeira, relacionados diretamente à FBN.
Os progenitores TVu 1190, CNC 0434 e Alagoano não diferiram significativamente da cultivar BRS Guariba, na média geral de NDFB. Na interação entre genótipos e fontes de nitrogênio observou-se que o progenitor TVu 1190 mostrou maior percentual de NDFB com a estirpe BR 3299 (72\%) quando comparada a BR 3267 (36,50\%) e que, para o tratamento controle, o percentual de NDFB foi igual ao obtido com a BR 3299. Infere-se que esta ocorrência tenha se dado em virtude da ação de bactérias nodulantes estabelecidas no solo.

Para o Pitiúba, as associações com as estirpes BR 3267 e BR 3299 apresentaram resultados mais favoráveis em relação às estirpes BR 3262 e INPA 03-11B. Os tratamentos controle (sem inoculação + sem $\mathrm{N}$ fertilizante) e com $\mathrm{N}$ fertilizante mostraram percentuais de NDFB similares $(59,50 \%)$ aos obtidos com as estirpes BR 3267 e BR 3299. Quanto ao CNC 0434, quando associado à estirpe BR 3262 revelou melhor resultado (70\%) comparado a BR 3299. O tratamento com $\mathrm{N}$ derivado do fertilizante foi superior ao tratamento com a BR 3299 e não diferiu das demais estirpes. $\mathrm{O}$ progenitor Alagoano mostrou que as associações com as estirpes BR 3299 e INPA 03-11B, bem como, com os tratamentos controle e $\mathrm{N}$ derivado de fertilizante, proporcionaram maior contribuição da FBN (7; 68; 70,5 e 61,5\%, respectivamente), em relação à estirpe BR 3262 (Tabela 3).

Entre as fontes de nitrogênio avaliadas, as médias do NDFB não apresentaram diferença estatística (Tabela 3). No entanto, associado à estirpe BR 3262, o progenitor CNC 0434 foi superior ao Pitiúba e ao Alagoano. Na associação com a BR 3299, observou-se maior teor de NDFB para TVu 1190, Alagoano e BRS Guariba. Associados à INPA 03-11B, os genótipos TVu 1190 e Alagoano destacaram-se do Pitiúba (Tabela 3). Estes resultados indicam que houve especificidade entre os

Tabela 3 - Nitrogênio derivado da fixação biológica (NDFB) em genótipos de feijão-caupi

\begin{tabular}{|c|c|c|c|c|c|c|}
\hline \multirow{2}{*}{ FONTES N } & \multicolumn{5}{|c|}{ GENÓTIPOS } & \multirow{2}{*}{ Média } \\
\hline & TVu 1190 & Pitiúba & CNC 0434 & Alagoano & BRS Guariba & \\
\hline & & 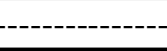 & PFB (\%) - & 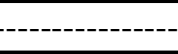 & 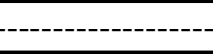 & \\
\hline BR 3262 & $55,50 \mathrm{ABab}$ & $32,00 \mathrm{Bb}$ & $70,00 \mathrm{Aa}$ & $27,00 \mathrm{Bb}$ & $69,00 \mathrm{Aa}$ & $50,70 \mathrm{~A}$ \\
\hline BR 3267 & $36,50 \mathrm{Ba}$ & $58,00 \mathrm{Aa}$ & $58,50 \mathrm{ABa}$ & $59,50 \mathrm{ABa}$ & $67,00 \mathrm{Aa}$ & $55,90 \mathrm{~A}$ \\
\hline BR 3299 & $72,00 \mathrm{Aa}$ & $55,00 \mathrm{Aab}$ & $34,50 \mathrm{Bb}$ & $73,00 \mathrm{Aa}$ & $69,50 \mathrm{Aa}$ & $60,90 \mathrm{~A}$ \\
\hline INPA $03-11 B$ & $65,00 \mathrm{ABa}$ & $32,50 \mathrm{Bb}$ & $61,00 \mathrm{ABab}$ & $68,00 \mathrm{Aa}$ & 55,50 Aab & $56,40 \mathrm{~A}$ \\
\hline $\mathrm{N}$ fertilizante & $56,00 \mathrm{ABa}$ & $59,50 \mathrm{Aa}$ & $71,00 \mathrm{Aa}$ & $70,50 \mathrm{Aa}$ & $63,00 \mathrm{Aa}$ & $64,00 \mathrm{~A}$ \\
\hline Controle & $72,00 \mathrm{Aa}$ & $59,50 \mathrm{Aa}$ & $49,50 \mathrm{Ba}$ & $61,50 \mathrm{Aa}$ & $69,00 \mathrm{Aa}$ & $62,30 \mathrm{~A}$ \\
\hline Média & $59,58 \mathrm{ab}$ & $49,42 \mathrm{~b}$ & $57,42 \mathrm{ab}$ & $59,92 \mathrm{ab}$ & $65,50 \mathrm{a}$ & - \\
\hline
\end{tabular}

Médias seguidas de letras distintas, minúsculas na linha e maiúsculas na coluna diferem entre si pelo teste de Tukey, a $5 \%$ de probabilidade 
genótipos e as diferentes estirpes. Sabe-se que a faixa hospedeira é bastante variável entre as espécies de rizóbio e as leguminosas, mas de modo geral tem sido observado especificidade simbiótica entre as espécies. Xavier et al. (2006) consideram que o genótipo da planta, pode desempenhar um papel essencial na seleção do microssimbionte.

Nos tratamentos controle e $\mathrm{N}$ fertilizantes, os genótipos não diferiram entre si. Também se observou que o tratamento com $\mathrm{N}$ fertilizante foi, na maioria dos casos, semelhante aos tratamentos com as estirpes, o que indica que o suprimento por meio biológico substitui completamente o $\mathrm{N}$ mineral. Haja vista que neste tratamento, utilizou-se a adubação nitrogenada recomendada (MELO et al., 2005) para feijão-caupi, assegurando à planta o suprimento nitrogenado necessário ao seu desenvolvimento. Trabalhos desenvolvidos por Soares et al. (2006) e Melo; Zilli (2009) com maiores teores de $\mathrm{N}$ ( $50 \mathrm{~kg} \mathrm{ha}^{-1}$ e $70 \mathrm{~kg} \mathrm{ha}^{-1}$, respectivamente) apresentaram resultados similares.

Por sua vez, o tratamento controle, na maioria das interações, foi similar aos tratamentos com inoculação, indicando que as estirpes nativas do solo foram capazes de suprir as plantas com o $\mathrm{N}_{2}$ fixado pela simbiose rizóbioleguminosa. Esta constatação foi um indicativo da alta capacidade dos rizóbios estabelecidos no solo promoverem a fixação de N, quando associados a plantas de feijão-caupi. Outros autores (ZILLI et al., 2006; SILVA et al., 2008; MELO; ZILLI, 2009 e ZILLI et al., 2009a) em trabalhos com FBN em feijão-caupi, também observaram esta ocorrência e concluíram que as estirpes nativas apresentam alta competitividade e potencial para FBN.

O comportamento das estirpes variou em função dos genótipos. Essas variações também foram observadas em outros estudos de FBN com cultivares de feijãocaupi (ALMEIDA et al., 2010; GUALTER et al., 2011; LACERDA et al., 2004; SOARES et al., 2006).
Os resultados deste estudo confirmaram que houve variação de resposta entre os genótipos e que provavelmente isto ocorreu devido à especificidade do macrossimbionte em relação ao microssimbionte. Segundo Xavier et al. (2006), a FBN é influenciada por características genotípicas da leguminosa e do rizóbio, haja vista que é um processo modulado por uma intensa troca de sinais moleculares, os quais se refletem nas diferentes respostas em relação ao hospedeiro, à especificidade e à eficiência simbiótica.

$\mathrm{Na}$ análise de variância dos componentes de produção, a interação entre os fatores fontes de nitrogênio e genótipos não foi significativa para as variáveis estudadas. Considerando-se os fatores de forma isolada, o fator genótipos teve efeito significativo para as variáveis, enquanto que o fator fontes de nitrogênio não mostrou efeito (Tabela 4).

Em massa de vagem e comprimento de vagem, o progenitor Alagoano apresentou melhores resultados que os demais genótipos, tendo sido observados incrementos na ordem de $30 \%$ para peso de vagem e de $32 \%$ para comprimento de vagem, em relação à cultivar BRS Guariba (Tabela 5).

As médias de comprimento de vagens obtidas com os progenitores TVu 1190, Pitiúba e Alagoano situaram-se na faixa de 23,05 a 31,46 cm, superando o padrão comercial de comprimento de vagens, que é de $18 \mathrm{~cm}$ (FREIRE FILHO et al., 2009). Infere-se que estes resultados estejam relacionados muito mais às características genéticas do que ao favorecimento da FBN no desenvolvimento da planta.

Conforme Sampaio et al. (2006), genótipos de porte semiereto e ereto geralmente apresentam comprimentos médios de vagens inferiores a $20 \mathrm{~cm}$, o que sugere que os resultados superiores a $20 \mathrm{~cm}$ obtidos para o TVu 1190 , de porte semiprostrado e para Pitiúba e Alagoano, de porte prostrado, seriam esperados. Oliveira et al. (2002) em estudo de avaliação de progenitores de feijão-caupi,

Tabela 4 - Resumo da análise de variância das variáveis de produção de genótipos de feijão- caupi associados a estirpes de rizóbio

\begin{tabular}{lcrrrrrr}
\hline \multirow{2}{*}{ Fontes de variação } & \multirow{2}{*}{ GL } & \multicolumn{5}{c}{ Quadrado Médio } \\
\cline { 3 - 8 } & & \multicolumn{1}{c}{ PV } & CV & NVP & NGV & M100S & RMG \\
\hline Blocos & 2 & $0,25^{\text {ns }}$ & $0,23^{\text {ns }}$ & $65,07^{\text {ns }}$ & $0,22^{\text {ns }}$ & $7,56^{*}$ & $4361,32^{*}$ \\
Fonte N (FN) & 5 & $0,14^{\text {ns }}$ & $1,32^{\text {ns }}$ & $33,39^{\text {ns }}$ & $0,99^{\text {ns }}$ & $0,75^{\text {ns }}$ & $815,21^{\text {ns }}$ \\
Genótipos (G) & 4 & $10,77^{*}$ & $450,75^{*}$ & $328,07^{*}$ & $20,92^{*}$ & $203,38^{*}$ & $23883,06^{*}$ \\
FN x G & 20 & $0,20^{\text {ns }}$ & $1,63^{\text {ns }}$ & $17,43^{\text {ns }}$ & $1,45^{\text {ns }}$ & $0,88^{\text {ns }}$ & $954,16^{\text {ns }}$ \\
Resíduo & 58 & 0,19 & 2,36 & 30,76 & 1,21 & 1,01 & 659,86 \\
CV $(\%)$ & & 10,38 & 6,56 & 38,66 & 6,51 & 5,26 & 18,65 \\
\hline
\end{tabular}

PV-peso de vagens $\left(\mathrm{g}\right.$ planta $\left.{ }^{-1}\right) ; \mathrm{CV}$-comprimento de vagens $\left(\mathrm{cm}\right.$ planta $\left.^{-1}\right)$; NVP-número de vagens por planta $\left(\mathrm{n}^{\mathrm{o}}\right.$ planta $\left.^{-1}\right)$; NGV-número de grãos por vagem $\left(\mathrm{n}^{\circ}\right.$ vagem $\left.^{-1}\right)$; M100S-peso de 100 sementes (g); RMG-rendimento médio de grãos ( $\left.\mathrm{kg} \mathrm{ha}^{-1}\right)$; ns-não significativo, ${ }^{*}$-significativo a $5 \%$ de probabilidade do teste $\mathrm{F}$ 
Tabela 5 - Valores médios de variáveis de produção de genótipos de feijão-caupi

\begin{tabular}{lcccccc}
\hline \multirow{2}{*}{ Genótipos } & MV & CV & NVP & NGV & M100S & RMG \\
\cline { 2 - 7 } & g planta $^{-1}$ & $\mathrm{~cm} \mathrm{planta}^{-1}$ & $\mathrm{n}^{\circ}$ planta $^{-1}$ & $\mathrm{n}^{\text {o }}$ vagem $^{-1}$ & $\mathrm{~g}$ & $\mathrm{~kg} \mathrm{ha}^{-1}$ \\
\hline TVu 1190 & $4,56 \mathrm{~b}$ & $23,05 \mathrm{~b}$ & $12,28 \mathrm{c}$ & $17,73 \mathrm{a}$ & $19,32 \mathrm{~b}$ & $1504,89 \mathrm{a}$ \\
Pitiúba & $3,90 \mathrm{c}$ & $23,32 \mathrm{~b}$ & $12,85 \mathrm{c}$ & $17,59 \mathrm{a}$ & $16,59 \mathrm{c}$ & $1031,11 \mathrm{~b}$ \\
CNC 0434 & $3,65 \mathrm{c}$ & $17,82 \mathrm{c}$ & $19,46 \mathrm{a}$ & $16,61 \mathrm{~b}$ & $15,52 \mathrm{c}$ & $1682,67 \mathrm{a}$ \\
Alagoano & $5,55 \mathrm{a}$ & $31,46 \mathrm{a}$ & $9,15 \mathrm{~d}$ & $17,25 \mathrm{a}$ & $24,10 \mathrm{a}$ & $948,44 \mathrm{~b}$ \\
BRS Guariba & $3,88 \mathrm{c}$ & $21,42 \mathrm{~b}$ & $17,98 \mathrm{~b}$ & $15,09 \mathrm{~b}$ & $20,11 \mathrm{ab}$ & $1720,00 \mathrm{a}$ \\
Média & 4,31 & 23,41 & 14,34 & 16,85 & 19,13 & 1377,42 \\
\hline
\end{tabular}

MV- massa de vagens; CV- comprimento de vagens; NVP- número de vagens por planta; NGV- número de grãos por vagem; M100S- massa de 100 sementes; RMG- rendimento médio de grãos. Médias seguidas de letras distintas, minúsculas na linha e maiúsculas na coluna diferem entre si pelo teste de Tukey, a $5 \%$ de probabilidade

observaram comprimento de vagem na faixa de 19 a $25 \mathrm{~cm}$. Gualter et al. (2011) analisando o efeito das mesmas estirpes avaliadas neste trabalho com a cultivar BRS Guariba, obtiveram valores muito próximos aos encontrados no mesmo.

Em número de vagem por planta, o progenitor CNC 0434 apresentou superioridade em referência aos demais genótipos, com média de 19,46 vagens planta $^{-1}$, valor este dentro da faixa de variação obtida por Gualter et al. (2011), com a cultivar BRS Guariba (11 a 31 vagens planta $^{-1}$ ). Para número de grãos por vagem, os progenitores TVu 1190, Pitiúba e Alagoano revelaram maior quantidade de grãos. Os progenitores apresentaram médias superiores a cultivar BRS Guariba e também superiores ao padrão comercial que é de 12 grãos (FREIRE FILHO et al., 2009). Sampaio et al. (2006) verificaram na avaliação de progenitores de feijão-caupi uma variação de 12 a 15 grãos por vagem para materiais de porte ereto e semiereto, respectivamente.

Em massa de 100 sementes, o Alagoano diferiu dos demais progenitores, porém não diferiu da cultivar avaliada. Gualter et al. (2011) observaram valores similares aos obtidos neste trabalho para a cultivar BRS Guariba. Santos et al. (2009), avaliando componentes produtivos de variedades de feijão-caupi, obtiveram valores coerentes com o peso de 100 sementes obtidos neste trabalho, tanto para os progenitores quanto para a cultivar avaliada.

Quanto ao rendimento médio de grãos, os progenitores TVu 1190 e CNC 0434 e a cultivar BRS Guariba apresentaram maiores rendimentos. O rendimento médio de grãos dos progenitores variou de 948,44 a $1504,89 \mathrm{~kg} \mathrm{ha}^{-1}$ o que é considerado uma boa produtividade com base na média da Região Nordeste, que se situa na faixa de 300 a $400 \mathrm{~kg} \mathrm{ha}^{-1}$ (FREIRE FILHO, 2011).
Na literatura tem sido observado que a utilização de inoculantes favorece significativamente o RMG. Soares et al. (2006) verificaram para a cultivar BR-14 Mulato, inoculada com as bactérias avaliadas neste trabalho, rendimentos na faixa de 700 a $900 \mathrm{~kg} \mathrm{ha}^{-1}$, semelhantes aos da testemunha com $70 \mathrm{~kg} \mathrm{ha}^{-1}$ de N. Gualter et al. (2008), observaram rendimentos em torno de $1200 \mathrm{~kg} \mathrm{ha}^{-1}$ para BRS Guariba inoculada com a BR 3262, enquanto que Melo e Zilli (2009) observaram produtividades de 1.200 a $1.400 \mathrm{~kg} \mathrm{ha}^{-1} \mathrm{com}$ as cultivares BRS Guariba e BRS Mazagão também inoculadas com as estirpes BR 3262 e BR 3267.

Portanto, embora não tenha sido significativo o efeito das fontes de nitrogênio para os componentes de produção, considera-se que os resultados obtidos com a inoculação foram similares aos da adubação nitrogenada, o que reflete que os progenitores das cultivares brasileiras de feijão-caupi, avaliados neste trabalho, apresentam eficiência simbiótica favorável à FBN.

\section{CONCLUSÕES}

1. Todos os progenitores das cultivares de feijão-caupi avaliados são responsivos à fixação biológica de nitrogênio, sendo que nos genótipos TVu 1190, CNC 0434, Alagoano e BRS Guariba, a FBN é responsável por cerca de $60 \%$ do $\mathrm{N}$ acumulado na parte aérea das plantas, e no genótipo Pitiúba este valor está em torno de $50 \%$;

2.Há indícios da existência de especificidade entre os progenitores de feijão-caupi e as estirpes de rizóbio, especialmente quanto ao acúmulo de $\mathrm{N}$ na planta;

3.O progenitor Alagoano apresenta melhores resultados na maioria dos componentes de nodulação e produção. No entanto, estes resultados não se refletem nas 
produtividades encontradas, principalmente em função do baixo número de vagens por planta.

\section{REFERÊNCIAS}

ALMEIDA, A. L. G. et al. Produtividade do feijão-caupi cv BR 17 Gurguéia inoculado com bactérias diazotróficas simbióticas no Piauí. Revista Brasileira de Ciências Agrárias, v. 5, n. 3, p. 364-369, 2010.

ALVES, B. J. R.; BODDEY, R. M.; URQUIAGA, S. The success of BNF in soybean in Brazil. Plant and Soil, v. 252, n. 1, p. 1-9, 2003.

BASTOS, E. A. et al. Evapotranspiração e coeficiente de cultivo de feijão-caupi no vale do Gurguéia-PI. Irriga, v. 13, n. 2, p. 182-190, 2008.

BELANE, A. K.; DAKORA, F. D. Symbiotic N2 fixation in 30 field-grown cowpea (Vigna unguiculata L. Walp.) genotypes in the Upper West Region of Ghana measured using ${ }^{15} \mathrm{~N}$ natural abundance. Biology and Fertility of Soils, v. 46, n. 2, p. 191-198, 2010.

BREMNER, J. M. Nitrogen total. In: SPARKS, D. L. Methods of soil analysis: Part. 3. Madison: SSA Book Series, 1996. p. 1085-1121.

CHAGAS JÚNIOR, A. F. et al. Eficiência agronômica de estirpes de rizóbio inoculadas em feijão-caupi no Cerrado, Gurupi-TO. Revista Ciência Agronômica, v. 41, n. 4, p. 709-714, 2010.

CLAESSEN, M. E. C. (Org.). Manual de métodos de análise de solo. 2. ed. rev. atual. Rio de Janeiro: Embrapa-CNPS, 1997. 212 p. (Embrapa-CNPS. Documentos, 1).

FREIRE FILHO, F. R. et al. Feijão-caupi: melhoramento genético, resultados e perspectivas. In: VIDAL NETO, F. das C.; BERTINI, C. H. C. de M.; ARAGÃO, F. A. S.; CAVALCANTI, J. J. V. (Ed.) $O$ melhoramento genético no contexto atual. Fortaleza: Embrapa - CNPAT, 2009. p. 25-59.

FREIRE FILHO, F. R. Feijão-caupi no Brasil: produção, melhoramento genético, avanços e desafios. Teresina: Embrapa Meio-Norte, 2011. 84 p.

GUALTER, R. M. R. et al. Inoculação e adubação mineral em feijão-caupi: efeitos na nodulação, crescimento e produtividade de grãos. Revista Scientia Agrária, v. 9, n. 4, 2008.

GUALTER, R. M. R. et al. Eficiência agronômica de estirpes de rizóbio em feijão-caupi cultivado na região da PréAmazônia maranhense. Pesquisa Agropecuária Brasileira, v. 46, n. 3, p. 303-308, 2011.

HERRIDGE, D. F.; PEOPLES, M. B.; BODDEY, R. M. Global inputs of biological nitrogen fixation in agricultural systems. Plant and Soil, v. 311, n. 1/2, p. 1-18, 2008.

HERRIDGE, D. F.; ROSE, I. Breeding for enhanced nitrogen fixation in crop legumes. Field Crops Research, v. 65. n. 2/3, p. 229-248, 2000.
LACERDA, A. M. et al. Efeito de estirpes de rizóbio sobre a nodulação e produtividade do feijão-caupi. Revista Ceres, v. 51, n. 293, p. 67-82, 2004.

MARTINS, L. M. V. et al. Contribution of biological nitrogen fixation to cowpea: a strategy for improving grain yield in the Semi-Arid Region of Brazil. Biology and Fertility of Soils, v. 38, n. 6, p. 333-339, 2003.

MELO, S. R. de.; ZILLI, J. É. Fixação biológica de nitrogênio em cultivares de feijão-caupi recomendadas para o Estado de Roraima. Pesquisa Agropecuária Brasileira, v. 44, n. 9, p. 1177-1183, 2009.

MELO, F. de B.; CARDOSO, M. J.; SALVIANO,A.A. C. Fertilidade do solo e adubação. In: FREIRE FILHO, F. R.; LIMA, J. A. de A.; RIBEIRO, V. Q. (Org.). Feijão caupi: avanços tecnológicos. Brasília: Embrapa Informação Tecnológica, 2005. p. 229-242.

NDIAYE, M. A. F.; SPENCER, M. M.; GUEYE, M. Genetic variability in dinitrogen fixation between cowpea [Vigna unguiculata (L.) Walp] cultivars determined using the nitrogen-15 isotope dilution technique. Biology Fertility Soils, v. 32, n. 4, p. 318-320, 2000.

OKITO, A. et al. Isotopic fractionation during N2 fixation by four tropical legumes. Soil Biology and Biochemistry, v. 36, n. 7, p. 1179-1190, 2004.

OLIVEIRA, A. P. et al. Avaliação de linhagens e cultivares de feijão-caupi, em Areia, PB. Horticultura Brasileira, v. 20, n. 2 , p. 180-182, 2002.

SAMPAIO, L. S. et al. Avaliação de linhagens de feijãocaupi em Igarapé Açu-PA. In: CONGRESSO NACIONAL DE FEIJÃO-CAUPI, 1., 2006, Teresina. Anais... Teresina: Embrapa, 2006. 1 CD ROM.

SANTOS, H. G. dos et al. (Ed.). Sistema Brasileiro de Classificação de Solos. 2. ed. Rio de janeiro: Embrapa Solos, 2006. 306 p.

SANTOS, J. F. et al. Produção e componentes produtivos de variedades de feijão-caupi na microregião Cariri paraibano. Engenharia Ambiental, v. 6, n. 1, p. 214-222, 2009.

SHEARER, G.; KOHL D. H. $\mathrm{N}_{2}$-fixation in field settings: estimations based on natural ${ }^{15} \mathrm{~N}$ abundance. Australian Journal of Plant Physiology, v. 13, p. 699-756, 1986.

SILVA, R. P. et al. Efetividade de estirpes selecionadas para feijão caupi em solo da região semi-árida do sertão da Paraíba. Revista Brasileira de Ciências Agrárias, v. 03, n. 02, p. 105-110, 2008.

SINGH, B. B. et al. Recent progress in cowpea breeding. In: FATOKUN, C. A.; TARAWALI, S. A.; SINGH, B. B.; KORMAWA, P. M.; TAMO, M. (Ed.). Challenges and opportunities for enhancing sustainable cowpea production. Ibadan: IITA, 2002. p. 22-40.

SOARES, A. L. de et al. Eficiência agronômica de rizóbios selecionados e diversidade de populações nativas nodulíferas em Perdões (MG). I - caupi. Revista Brasileira de Ciência do Solo, v. 30, n. 5, p. 795-802, 2006. 
VARGAS, M. A. T. et al. Inoculação de leguminosas e manejo de adubos verdes. In: SOUSA, D. M. G.; LOBATO, E. (Ed.) Cerrado: correção do solo e adubação. 2. ed. Brasília: Embrapa Informação Tecnológica, 2004. p. 97-127.

XAVIER, T. F. et al. Inoculação e adubação nitrogenada sobre a nodulação e a produtividade de grãos de feijão-caupi. Ciência Rural, v. 38, n. 7, p. 2037-2041, 2008.

XAVIER, G. R. et al. Especificidade simbiótica entre rizóbios e acessos de feijão-caupi de diferentes nacionalidades. Revista Caatinga, v. 19, n. 1, p. 25-33, 2006.

YUSUF, A. A. et al. Genotype effects of cowpea and soybean on nodulation, $\mathrm{N}_{2}$-fixation and $\mathrm{N}$ balance in the northern
Guinea savanna of Nigeria. Journal of Agronomy, v. 7, n. 3, p. 258-264, 2008.

ZILLI, J. É. et al. Contribuição de estirpes de rizóbio para o desenvolvimento e produtividade de grãos de feijão-caupi em Roraima. Acta Amazônica, v. 39, n. 4, p. 749-758, 2009 a.

ZILLI, J. É. et al. Eficiência simbiótica de estirpes de Bradyrhizobium isoladas de solo do Cerrado em caupi. Pesquisa Agropecuária Brasileira, v. 41, n. 5, p. 811-818, 2006.

ZILLI, J. É. et al. Fixação biológica de nitrogênio. In: ZILLI, J. É.; VILARINHO, A. A.; ALVES, J. M. A. (Ed.) A cultura do feijão caupi na Amazônia brasileira. Boa Vista: Embrapa Roraima, 2009b. p. 185-221. 